\title{
Making IR Content Discoverable Improving institutional repository content discovery through your local catalog and WorldCat
}

\author{
By Fang Wang
}

I nstitutional repositories (IRs) host a lot of unique and valuable digital content. More and more law libraries are implementing IRs to meet the needs for open access, long-term preservation, electronic publishing, and libraries' evolving role in teaching and research. But most patrons don't know where or how to find that content. So librarians must make the IR content more discoverable (and easy to find).

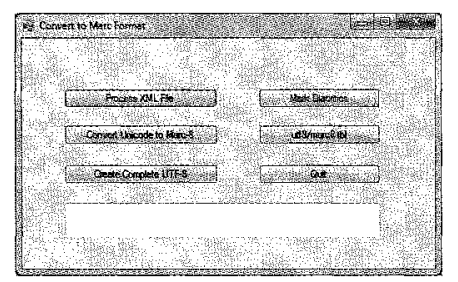

Figure 1: MARC-DC converter

The local catalog and WorldCat are essential tools patrons use to find library materials. Besides popular search engines, such as Google, the library catalog is another great venue to increase IR access and presence. Making IR content searchable in the local catalog and WorldCat makes them more discoverable to law library patrons and beyond. Adding item links to existing catalog records showing the availability of the IR items seems to be a standard practice. But not all repository items have corresponding MARC records in the local catalog. The IR has a lot of unique digital content not included in the catalog. Cataloging each IR item appears to be time consuming and a duplicated effort. So how can we make IR content searchable through the local catalog as well as in WorldCat?

\section{Making IR Content Discoverable} in the OASIS Local Catalog

Texas Tech University School of Law Library's IR, "ScHOLAR," at repository.law.ttu.edu, was established at the beginning of 2010 and has been up and running for more than two and a half years. ScHOLAR stands for Scholarship and Historical Online Legal Access Repository. It was built using DSpace, a popular open source repository platform developed by the Massachusetts Institute of Technology and Hewlett-Packard. It was designed as a central location to preserve, share, and promote Tech Law's digital materials,

including faculty scholarship, student writings, institutional history, and more. The repository currently has 23 collections containing more than 1,800 digital items.

In 2011, I attended metadata training offered by Texas Digital Library. At the onsite training, I learned that a university library had been working on the discovery of its IR content. The library developed an in-house program (an .exe script) to automatically batch transfer IR records from Dublin Core (DC) to MARC. The script was created in Microsoft Visual Studio as a Windows forms application for the library's Electronic Thesis and Dissertation (ETD) collection. The library staff generously shared the source code of the program and the mapping document (Excel spreadsheet) they had created that laid out what DC element was mapped to a MARC element.

Because the program was particularly designed for ETD records, some modifications to the program were needed-e.g., fields such as graduation year, dissertation committee, etc., needed to be removed. The assistant director for collection services and I worked closely to create a new mapping document tailored for ScHOLAR collections. With the aid of this crosswalk document, the programmer was able to modify the program to make it work. Figure 1 shows what the program looks like. The only two buttons used are "process XML file" and "quit." The rest of the buttons were not needed for the ScHOLAR to OASIS conversion process because they were created for the ETD collection.

I first downloaded all IR item metadata in XML format. In DSpace, there is an option to export metadata under the administrative interface.
Because the exported XML files were individual files, they needed to be jointed into one XML file that contains all the metadata records. Then this XML file was run through the modified MARC-DC converter. Click on "Process XML file," select the XML file to be converted, select the destination of the output file, and then the program will automatically create a MARC file with a file extension .mrk. Open this .mrk file in MarcEdit and correct any small errors, such as spacing issues, if necessary, then save it to an .mrc file. The assistant director for collection services then uploaded this final MARC file that contains all ScHOLAR records to the local catalog OASIS.

When conducting a search in OASIS, the search results reflect the IR records. See Figure 2, a sample record for a law school hooding ceremony record. Clicking on "Connect to this title in ScHOLAR" will take the patron to the item in the IR.

\section{Making IR Content Discoverable in WorldCat} Once the IR content was searchable in the local catalog OASIS, the next step was to make the content also searchable in OCLC WorldCat. OCLC has a selfservice tool for uploading the digital repository metadata to WorldCat to maximize web visibility. It is called the OCLC Digital Collections Gateway and has been adopted by many libraries to improve the digital repositories' discoverability. It was originally designed for OCLC CONTENTdm collections but was later enhanced to be used for any OAI-compliant repository. This service is available at no charge and doesn't require an OCLC membership.

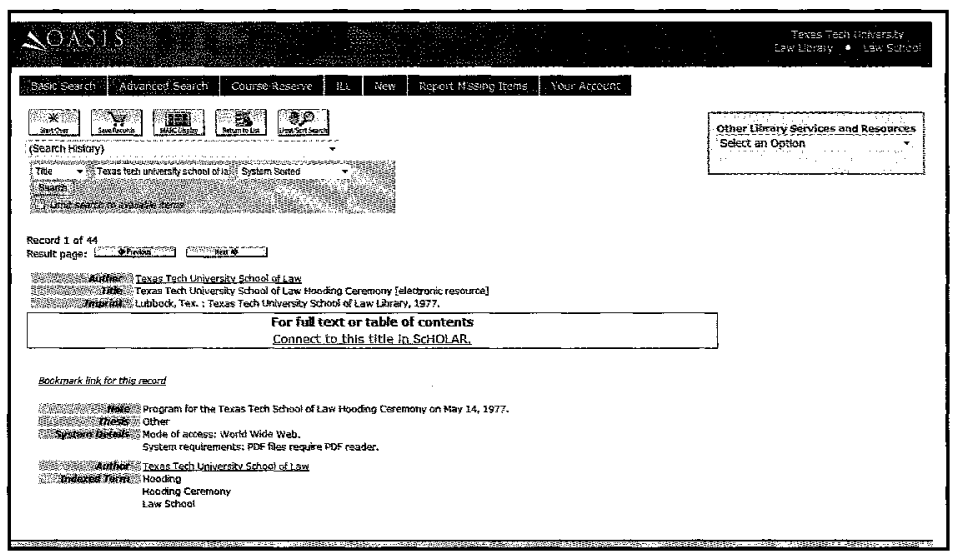

Figure 2: IR hooding ceremony record reflected in the local catalog 


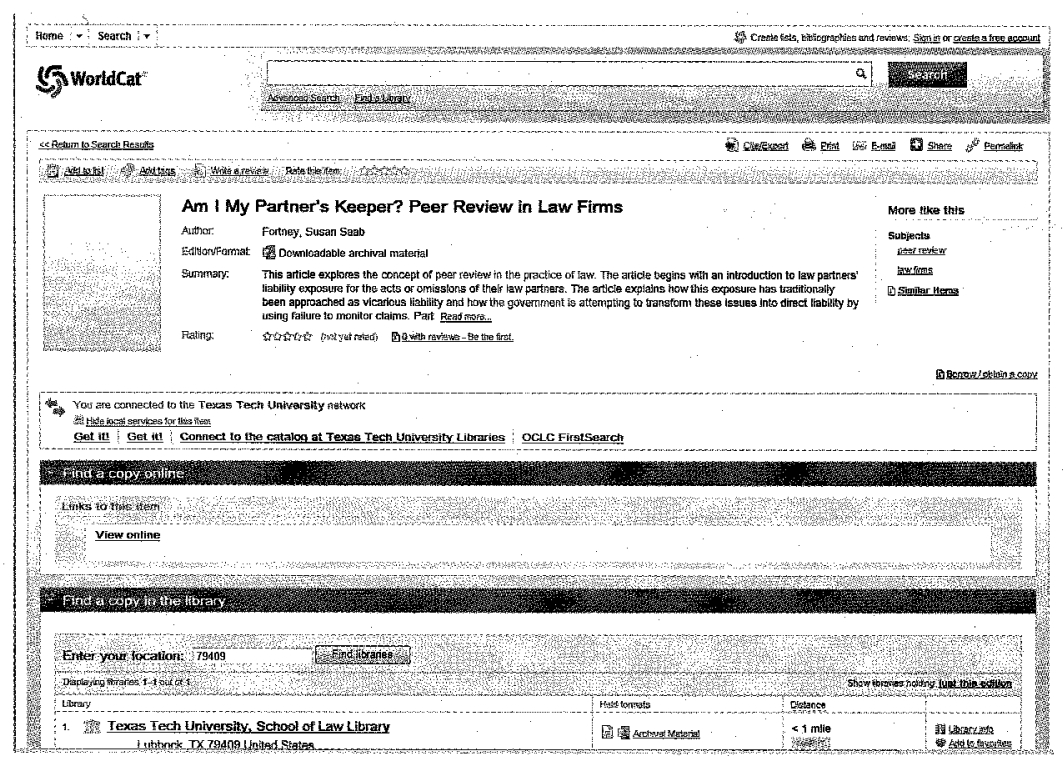

Figure 3: Law school faculty scholarship article reflected in WorldCat

According to OCLC, 20 million digital repository collection records have been added to WorldCat through the Digital Collections Gateway.

OCLC provides tutorials and web sessions to help users with learning and using this tool. Before registering and using the Gateway, the OAI setting in the IR needs to be enabled to ensure that the repository is OAI-PMH compliant. Then the institution needs to register to use the Gateway. The login information will be provided in a welcome email, and the IR profile needs to be set up after logging in.

I set up the profile for ScHOLAR after registering in the OCLC Digital
Collections Gateway. Information needed for setup included an OAI-PMH base URL for the digital repository and the type of the IR (DSpace, Fedora, EPrints, Digital Commons, or other). I then worked closely with the assistant director for collection services on setting up, reviewing, and tweaking the mappings for each collection. The metadata was synchronized after the mappings were approved. After the ScHOLAR content became searchable in WorldCat, the repository items were shown as "downloadable archival materials" in the search results. One click on an item opens a record, and the link "view online" takes the patron directly to the item in the ScHOLAR repository. See Figure 3 for an example of the law school faculty scholarship record.

Synchronization schedules can be set up to harvest the metadata periodically, whether it be monthly, quarterly, semiannually, or annually. If new items are added to the IR, the Gateway will then automatically re-sync the collection based on the schedule.

\section{Future Steps}

Making IR content more discoverable is crucial to the success of any IR. The local catalog and WorldCat can drive more traffic to the IR to boost the exposure and use of the legal scholarship and other unique content. For future steps, any new repository content will continue to be made available via the local catalog OASIS and WorldCat. One improvement will be to add thumbnail displays in WorldCat for IR picture collections. Currently, WorldCat doesn't support picture thumbnail for nonCONTENTdm collections, but a local customization can be done to achieve this result. OASIS and WorldCat referral traffic statistics will also be collected to measure the success of this project.

Fang Wang (fang.wang@ttu.edu) is digital information librarian at Texas Tech University School of Law Library. in Lubbock. She would like to thank Sue Kelleher for her belpful input and comments for this article.

\section{announcement}

\section{The 2012 AALL Election Schedule and Candidates}

2012 Election Schedule

November 1, 2012

Ballots distributed electronically to all voting members.

\section{November 29, 2012}

Deadline for receipt of electronic ballots at AALL. Ballots tabulated at AALL and results of elections announced immediately. (Biographies and statements of all AALL Executive Board candidates will be posted soon at https://vote. aallnet.org/aall/bios.asp.)

If you do not have email or do not wish to participate in an online election, please contact Hannah Phelps, AALL's membership services coordinator, by October 14, and headquarters will provide paper ballots. Phelps can be reached at hphelps@aall.org or at 312/205-8022.

\section{Candidates}

The AALL Nominations Committee nominated the following individuals for office in AALL:

\section{Vice President/President-Elect \\ Julie Pabarja, research services manager, DLA Piper, Chicago}

Holly M. Riccio, library/calendar manager of Northern California, O'Melveny \& Myers LLP, San Francisco

\section{Treasurer}

Joan M. Bellistri, law librarian, Anne Arundel County Public Law Library, Anne Arundel County Circuit Court, Annapolis, Maryland
Gail Warren, state law librarian, Virginia State Law Library, Richmond

\section{Executive Board Member}

Femi Cadmus, Edward Cornell law librarian and associate dean for library services, Cornell University Law Library, Ithaca, New York

Kenneth J. Hirsh, director of the law library and information technology, University of Cincinnati College of Law, Robert S. Marx Law Library, Cincinnati, Ohio

Allen R. Moye, director of the law library and associate professor of law, DePaul University College of Law, Rinn Library, Chicago

Roger Vicarius Skalbeck, associate law librarian, Georgetown University Law Library, Washington, D.C. 